\title{
Can COVID-19 Cause Parkinson's Disease Years Later?
}

\author{
Marcos Altable* and Juan Moisés de la Serna \\ Private Practice of Neurology, Neuroceut (Virgen de África Clinic), Spain \\ International University of La Rioja, Spain
}

\section{SHORT COMMUNICATION}

As COVID-19 advances around the world, there are several points that the current COVID-19 pandemic may influence on the global burden of Parkinson's disease (PD).

Preliminary studies have suggested that severe acute respiratory syndrome coronavirus 2 (SARS-CoV-2), which is the etiologic agent of COVID-19, may have potential neurotropism in humans, although this feature has not yet been conclusively demonstrated. (one). Like other respiratory viruses, SARS-CoV-2 can reach the central nervous system (CNS) through the blood or peripheral nerves, such as the nerve endings of the olfactory epithelium of the nasal passages [1-3]. The hypothesis of the olfactory pathway for SARS$\mathrm{CoV}-2$ neuro invasion is supported by the fact that several patients with COVID-19 infection have experienced decreased or total loss of smell (hyposmia/anosmia) and altered taste or dysgeusia. The exciting aspect of this route (from the nasal cavity to the olfactory bulb, then to the cerebral cortex and finally to the brain stem) is the possible presence of the virus in the brain stem, which contains the nuclei of neurons responsible for respiration control. In fact, more than half of the patients with COVID-19 infection show respiratory distress [4].

A large number of studies suggest that the pathological process of PD can be modulated (or initiated) by viruses or other pathogens. The first evidence of a possible link between virus and PD comes from the lethargic encephalitis epidemic, after the 1918 influenza outbreak (Spanish flu) [5].

On that occasion, almost all the patients who had an acute episode of this encephalitis developed post-encephalitic parkinsonism, a condition that closely resembled the clinical picture of PD and the periods of negative symptoms or catatonia of schizophrenia, both mediated by the impaired dopaminergic transmission. Administration of non-lethal doses of the highly pathogenic H5N1 influenza virus in the nostrils of mice has been shown to induce microglial activation (brain cells that protect and communicate with neurons) as well as phosphorylation and aggregation of alpha-synuclein in

virus-infected brain areas, characteristic of PD [6]. Viruses, besides, persisted long after infection resolved. Significant loss was also observed and enduring of dopaminergic neurons in the pars compact substantia nigra (SNpc), which is currently considered the cause of PD. This is not limited to influenza, as some of the cardinal motor symptoms and brain tissue characteristics of PD have also been associated with other viruses (Coxsackie virus, West Nile virus, Japanese encephalitis B virus, encephalitis virus Saint Louis and HIV) [7,8]. Furthermore, Fazzini et al. [9] described the presence of anti-coronavirus antibodies in samples from people with PD.

Thus, SARS-CoV-2 infection could contribute to the development of PD, either directly (due to the physical presence of the virus in the brain) or indirectly (inducing a long-lasting inflammatory process in the brain). However, this alone would probably, in most cases, be insufficient to develop PD. Therefore, it has been suggested virus would act as a facilitator in the pathogenesis of PD, either acting at the time of the triggering event (for example, a viral infection) or even years later. Such processes generally occur in the prodromal or asymptomatic phase of PD [10]. Among the various facilitators that can affect the progression of PD, ageing and cellular senescence have by far the most recognized impact.

In 2016, 6 million individuals had Parkinson's disease, compared with 2.5 million in 1990 [11]. The continuous ageing of world population sustains such exponential growth. Regardless of PD, world life expectancy has increased approximately six years in the past two years. Thus, as longevity increases, so does the number of people live with PD. Since SARS-CoV-2 can induce an exaggerated inflammatory reaction in patients with severe COVID-19 infection, SARS-CoV-2 could be a triggering event for the underlying neurodegenerative process in PD. In addition, studies
Quick Response Code:

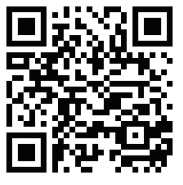

Address for correspondence: Marcos Altable, Private Practice of Neurology, Neuroceut (Virgen de África Clinic), Spain

Received: August 01, $2020 \quad$ Published: August 11, 2020

How to cite this article: Marcos A, Juan M de la S. Can COVID-19 Cause Parkinson's Disease Years Later?. 2020 - 2(4) OAJBS.ID.000206. DOI: 10.38125/OAJBS.000206 
showed that other human coronaviruses might remain dormant in leukocytes, and therefore may be predisposed to producing latent or persistent CNS infections [12]. Previous studies described that people who born or young at the time of the 1918 influenza outbreak had a 2 to 3 times greater risk of developing PD than those born before 1888 or after 1924 [13]. With all the above, it is worth considering whether survivors of COVID-19 could represent a part of the future population of patients with PD.

\section{REFERENCES}

1. Khan S, Gomes J (2020) Neuropathogenesis of SARS-CoV-2 infection. eLife 9: e59136.

2. Cain MD, Salimi H, Diamond MS, Klein RS (2019) Mechanisms of pathogen invasion into the central nervous system. Neuron 103(5): 771783.

3. Dubé M, Le Coupanec A, Wong AHM, Rini JM, Desforges M, et al. (2018) Axonal transport enables neuron-to-neuron propagation of human coronavirus 0C43. J Virol 16: e00404-18.

4. Wang D, Hu B, Hu C, Zhu F, Liu X, et al. (2020) Clinical characteristics of 138 hospitalized patients with 2019 novel coronavirus-infected pneumonia in Wuhan, China. JAMA.

5. Boyd DF, Wilson TL, Thomas PG (2020) One hundred years of (influenza) immunopathology. Advances in Virus Research 107: 247-284.
6. Jang H, Boltz D, Sturm-Ramirez K, Shepherd KR, Jiao Y, et al. (2009) Highly pathogenic H5N1 influenza virus can enter the central nervous system and induce neuroinflammation and neurodegeneration. Proc Natl Acad Sci 106: 14063-14068.

7. Limphaibool N, Iwanowski P, Holstad MJV, Kobylarek D, Kozubski W (2019) Infectious etiologies of parkinsonism: pathomechanisms and clinical implications. Front Neurol 10: 652.

8. Jang H, Boltz DA, Webster RG, Smeyne RJ (2009) Viral parkinsonism. Biochim Biophys Acta 1792, 714-721.

9. Fazzini E, Fleming J, Fahn S (1992) Cerebrospinal fluid antibodies to coronavirus in patients with Parkinson's disease. Mov Disord 7(2): 153158.

10. Victorino, Daniella Balduino et al. (2020) COVID-19 and Parkinson's Disease: Are We Dealing with Short-term Impacts or Something Worse? J Parkinsons Dis 10(3): 899-902.

11. GBD 2016 Neurology Collaborators (2019) Global, regional, and national burden of neurological disorders, 1990-2016: a systematic analysis for the Global Burden of Disease Study 2016. The Lancet Neurology 18(5): 459-480.

12. Desforges M, Le Coupanec A, Dubeau P, Bourgouin A, Lajoie L, et al. (2019) Human coronaviruses and other respiratory viruses: underestimated opportunistic pathogens of the central nervous system? Viruses 12: E14.

13. Martyn CN (1997) Infection in childhood and neurological diseases in adult life. Br Med Bull 53: 24-39. 